UNIVERSIDADE ESTADUAL DE FEIRA DE SANTANA

Autorizada pelo Decreto Federal $n^{\circ} 77.496$ de 27/04/76

Recredenciamento pelo Decreto $n^{\circ} 17.228$ de 25/11/2016

PPPG

PRÓ-REITORIA DE PESQUISA E PÓS-GRADUAÇÃO

COORDENAÇÃO DE INICIAÇÃO CIENTÍFICA

XXIV SEMINÁRIO DE INICIAÇÃO CIENTÍFICA DA UEFS

SEMANA NACIONAL DE CIÊNCIA E TECNOLOGIA - 2020

\title{
O PAPEL DO BRINCAR CRIATIVO NA CONSTRUÇ̃̃O DE UMA EDUCAÇÃO INFANTIL VOLTADA PARA OS DIREITOS HUMANOS
}

\author{
Joana Carla de Jesus Assis ${ }^{1}$; Carlos César Barros ${ }^{2}$ \\ 1. Bolsista PIBIC/CNPq, Graduanda em Psicologia, Universidade Estadual de Feira de Santana, e-mail: \\ joannaassis2014@gmail.com \\ 2. Orientador, Departamento de Ciências Humanas e Filosofia, Universidade Estadual de Feira de Santana, e-mail: \\ carlosbarros@uefs.br
}

PALAVRAS-CHAVE: brincar; criança; criatividade.

\section{INTRODUÇÃO}

A pesquisa a ser apresentada no presente resumo foi elaborada com base no projeto de pesquisa "Educação para os direitos humanos: eticidade e ação criativa nos diferentes contextos do brincar", coordenado pelo Prof. Dr. Carlos César Barros. Objetiva pensar a importância do conceito de "brincar" na construção de valores que favoreçam a elaboração de um modelo de educação infantil voltado para os direitos humanos.

Para a efetivação desse objetivo, foi realizado um aprofundamento teórico no conceito do "brincar" e suas implicações para o desenvolvimento infantil sob a ótica da teoria das relações objetais do psicanalista inglês Donald Winnicott (1896-1971) e nas reflexões do filósofo Walter Benjamin (1892-1940). Essa imersão na obra dos dois autores representa uma conversa entre a análise psicológica de Winnicott e a filosofia revolucionária de Benjamin. Esse diálogo situa a pesquisa num espaço que é próprio à teoria crítica, onde os debates sobre emancipação e reconhecimento são realizados desde as primeiras gerações.

A pesquisa busca demonstrar correlações entre o "brincar" e o papel dos jogos, dos brinquedos e das brincadeiras como forma das crianças mediarem sua relação com o mundo. Entender como o espaço criativo do brincar pode se relacionar com o que escreve Benjamin (2009) a respeito da capacidade infantil de reinventar sentidos para coisas cujos sentidos já estão dados na cultura adulta.

Isso requer uma retomada de aspectos específicos da psicanálise winnicottiana, como o conceito de objetos e fenômenos transicionais. A hipótese a ser trabalhada é a de que nessa esfera, que não é nem seu interior nem o mundo externo, a criança vai formar 
valores que influenciarão seu modo de se relacionar com o meio social. Benjamin (2009) pensa os jogos e brinquedos como instrumentos através dos quais as crianças experimentam desde muito cedo sentimentos como o amor e a hostilidade.

O debate sobre reconhecimento, trabalhado no plano geral do projeto de pesquisa, cabe aqui para pensar como essa relação primária (mãe e bebê) determina as noções infantis de auto respeito e respeito para com outros. Axel Honneth (1949-), em seu "Luta por Reconhecimento" (2003), busca demonstrar o papel das relações afetivas, que Donald Winnicott tanto enfatiza, como fundamentais no desenvolvimento da autonomia e dos processos de reconhecimento social e político.

Portanto, o plano em questão busca se justificar através da imersão no conceito do brincar criativo, seus desdobramentos e as possíveis correlações com a teoria do reconhecimento e com uma pedagogia revolucionária que compreenda as crianças como seres autônomos. Como indivíduos cujo desenvolvimento vai além do que a "pedagogia colonial" pode compreender (Benjamin, 2009).

\section{MATERIAL E MÉTODOS OU METODOLOGIA (ou equivalente)}

A revisão bibliográfica foi realizada com base na metodologia científica de Marconi e Lakatos (2006), que definem como etapas do processo de produção: a identificação da bibliografia; a análise de resumos e de bibliografias; localização das obras relevantes para a pesquisa; compilação; fichamento; e análise seguida de interpretação das mesmas.

No que diz respeito à escolha da bibliografia, tendo em vista a complexidade e extensão das produções dos autores principais, foram selecionadas obras específicas para servirem de fontes primárias. São elas: "O Brincar e a Realidade” (Winnicott, 1975) e "Reflexões sobre a Criança, o Brinquedo e a Educação" (Benjamin, 2009). O livro "Luta por Reconhecimento" (Honneth, 2003) também foi utilizado como referência para pensar as relações afetivas na teoria das relações objetais favorecendo o processo de reconhecimento e emancipação da criança. Também foram utilizados artigos de outros autores como leituras secundárias.

\section{RESULTADOS E/OU DISCUSSÃO (ou Análise e discussão dos resultados)}

Winnicott (1975) escreve sobre como o processo quase acidental de introdução de um objeto na boca, com o intuito de se satisfazer, leva à transição do autoerotismo infantil para a satisfação com algo de concreto no mundo, ainda que naquele momento o bebê 
não perceba isso. Até aquele momento, a criança acredita que todo o seu mundo, o seio da mãe incluso, foi criado por ela.

Ele reconhece como objetos e fenômenos transicionais tudo que é fantasiado e utilizado no período de tempo que separa o uso acidental do punho e o apego aos objetos que mais tarde serão introduzidos pela mãe. O autor aponta tais objetos e fenômenos como um terceiro aspecto constituinte da vida dos sujeitos, uma zona de experimentação localizada entre a realidade interna e a vida externa. É a "área que é concedida ao bebê, entre a criatividade primária e a percepção objetiva baseada no teste da realidade" (WINNICOTT, 1975, p.26).

Para Honneth (2003), o desenvolvimento satisfatório dos processos da criança com os objetos transicionais contribui positivamente para consolidar relações de amor autônomas entre mãe e bebê. Seu pensamento se justifica pelo fato de que o processo em que a criança se permite estar sozinha só pode ocorrer confortavelmente mediante uma confiança na dedicação materna. Confiança num afeto que se manifesta mesmo na ausência dessa mãe. Essa crença possibilita não só que a criança esteja só sem receios, mas que se torne segura de si. O tipo de segurança que só experimenta a criança que se acredita amada e o tipo de relação que fundamenta a importância do amor como forma de reconhecimento.

No terreno em que a mãe tenta introduzir novos objetos ou formas de brincar surge a interação lúdica, que é própria das relações interpessoais. Essa dinâmica compreende o que Winnicott (1975) nomeou playground, o primeiro espaço potencial para a brincadeira, que comumente surge da relação entre a mãe e o bebê. $\mathrm{O}$ autor entendia que "a importância do brincar é sempre a precariedade do interjogo entre a realidade psíquica pessoal e a experiência de controle de objetos reais" (WINNICOTT, 1975, p. 79).

O brincar é um espaço de experimentação onde a criança mescla elementos de sua esfera psíquica e fragmentos que absorveu do mundo em que vive. A estes as crianças atribuem valores singulares, diferentes daqueles que já estão determinados pela cultura adulta. Essa capacidade de ressignificar tem um lugar importante nas reflexões de Walter Benjamin sobre a relação entre crianças e brinquedos. Benjamin esperava do século XX "uma superação efetiva daquele equívoco básico que acreditava ser a brincadeira da criança determinada pelo conteúdo imaginário do brinquedo, quando, na verdade, dá-se o contrário" (BENJAMIN, 2009, p. 93). É a capacidade criativa da própria criança que cria o brinquedo. 
Em seus ensaios, Benjamin descreve o brincar como "um mudo diálogo de sinais entre a criança e povo" (BENJAMIN, 2009, p. 94). Se são os brinquedos um meio de dizer o que constitui essas crianças, por que não dizer que também o é o brincar? Se os brinquedos são a comunicação muda das crianças, o brincar em si, com suas histórias e murmúrios barulhentos tem muito o que dizer aos adultos. São meios de compreender as crianças, de uma vez e não mais tarde, como formadoras de seus próprios valores. E meios de construir uma educação que as respeite e, assim, possa ensiná-las a respeitar a todos.

\section{CONSIDERAÇÕES FINAIS (ou Conclusão)}

A forma como as crianças aprendem a interagir com a realidade é marcada desde o princípio pelo meio social. As sensações de segurança, conforto e pertencimento são oferecidas pelo colo e, mais tarde, é o distanciamento, que também é próprio do meio social, que cede espaço para que a criança galgue seus próprios mecanismos de compreender o mundo. Cabe à nossa pesquisa atentar para essas formas singulares de compreensão, buscar apreender (o que for possível na nossa lógica adulta de pensamento) os valores que as crianças elaboram quando se relacionam, e como contornam/absorvem as questões sociais para as quais a nossa "pedagogia colonial" só pensa em lhes oferecer respostas quando adultos.

A concepção do amor como a primeira forma de reconhecimento recíproco (Honneth) também é importantíssima, quando almejamos construir uma educação em que os sujeitos não só reconheçam a si mesmos de forma autônoma, pois considerar o reconhecimento como oriundo dos laços afetivos é essencial para perceber a autonomia dos outros e respeitá-los.

\section{REFERÊNCIAS}

BENJAMIN, Walter. Reflexões sobre a Criança, o Brinquedo e a Educação. 2. ed. São Paulo: Editora 34, 2009. Tradução, apresentação e notas: Marcus Vinicius Mazzari.

HONNETH, A. Luta por reconhecimento: a gramática moral dos conflitos sociais. São Paulo: Editora 34, 2003.

MARCONI, M.A.; LAKATOS, E.M. Metodologia do trabalho científico: procedimentos básicos, pesquisa bibliográfica, projeto, relatório, publicações e trabalhos científicos. 6. ed. São Paulo: Atlas, 2006.

WINNICOTT, D.W. O brincar e a realidade. Rio de Janeiro: Imago, 1975. 